\title{
The Impact of Risk Management Practices on the Performance of Construction Projects
}

\author{
NASSER ALSAADI ${ }^{1}$, NORHAYATIZAKUAN ${ }^{2}$ \\ ${ }^{1}$ Faculty of Management, UNIVERSITITEKNOLOGI MALAYSIA, E-mail: nasseralsaadi2020@hotmail.com \\ ${ }^{2}$ Faculty of Management, UNIVERSITITEKNOLOGI MALAYSIA, E-mail: norhayayatimz@utm.my
}

\begin{abstract}
Construction performance and risk management has been widely discussed in the literature from various perspectives. The main objective of performing risk management in construction industry is to ensure timely delivery of good construction within sepecific budget. However, the failure of many construction projects in meeting deadlines, cost and quality targets is continuously on the rise and there are signs of accentuating year after year suffering significant financial losses of construciton works in Oman. Therefore, there is a need for empirical evidences to explain the relationship between risk management and project performance. This study applied quantitative methods to examine this relationship. Construciton companies from grade excellent to grade second in Oman haven included in the survey. The result revealed that practicing risk managementimprove the performance of construciton project significantly. Based on this result it is essential to hire qualified project managers who has sufficient knowledge in risk managmeent and its main activities.
\end{abstract}

Keywords: Risk Management, Construction Projects, Project Performance

JEL Classification: N6 


\section{Introduction}

The construction industry is the pillar of success of modern countries. Since the rapid economic development has increased the demand for construction of infrastructure and facilities around the globe. The construction industry also provides the basic living conditions for the sustainability and development of human life on the earth. To cope with an ever-increasing population, pressure on land, and growing economic activity, construction projects are in increasing demand and activities are booming in many countries. Projects could face many types of risks in all stages of project implementation thus these risks should be identified, evaluated and carefully handled based on the knowledge available at this stage (Hessellund, 2017). This goal can be achieved by starting the risk management process at the very beginning of a project's life cycle to take into account the process of participation of all stakeholders in this process (Kotlarsky et al., 2020). At the initial stage of the project, the associated risks are based on uncertainties that limit decision-making on previous projects. This uncertainty can be defined as a state for which there is no information (Desai \& Kashiyani, 2015).Oman at present is desperately looking for development projects in many other areas especially those relate to petrochemical and gas industries, water, wastewater collection and distribution, roads and highways infrastructures, tourism and residential. As a result, there is an unprecedented number of large-scale projects are currently under construction or in the planning and contract award stage.Additionally, it has been witnessed that Oman has not only opened its doors to foreign investments since the year 2007 especially in the gas and tourism sectors but also has joined both regional and global free trade organizations. Following these development in the countries it is expected that Oman will produce an unprecedented growth in the construction activities as shown in Figure-1 below.

Figure-1: Construction industry of Oman (past, present and future) (Source: Cserhati and Szabo, 2013)

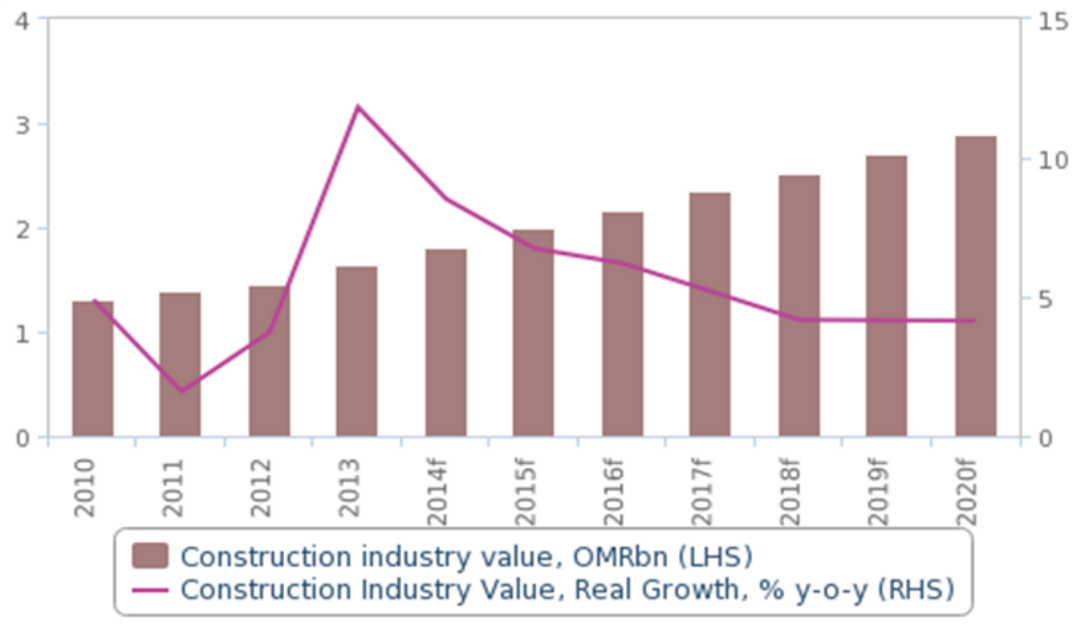

A study that has been conducted by Singh \& Hong, 2020 reported that survey carried out on risk management practices within project environments in Oman showed that the majority of construction organizations in Oman rely on intuition, subjective judgment and practical experience in assessing project risks. Furthermore, it was also found that the risk management practices within these companies were found neither formal nor systematic but very much on ad hocor firefighting basis and accordingly their focus in on the avoidance of risk as a process rather than mitigating those circumstances that give rise to the occurrence of risk.

The concept of risk management in Oman is relatively new and thus it was not practiced by most contractors then with the exception few and this resulted in poor definition of the project objectives, poor cost estimates and adversarial relationships between these corporations and their clients. Ten years on, however, project risk management scenario in Oman today doesn't seem to have changed much and accordingly project risk management is still a critical issue faced by most of the construction companies in Oman today. 
In the context of construction industry, management it becomes apparent that construction risk management concerns mainly with the management of activities and resources of a construction organization in mitigating the impacts that can affect the achievement of goals and objectives of a project. The review of literature shows that the main objective of performing risk management in construction industry is to ensure timely delivery of good construction within budget allocated, they suggested there is a need for new theory to explain the relationship between risk management and project performance to answer the various issues and problem in construction industry. Therefore, this study will contribute to the knowledge of risk management in construction project be providing an empirical evidence in the significant role of risk management on the performance of construction projects.

\section{The Aim of Research}

A project is a fixed-time group activity designed to produce a unique product, service or result. Fixed-time means that a project always has a specific beginning and end in time, and therefore defined scope and resources within these two points. Project management requires different knowledge, different skills and performs a different task (Kerzner, 2018). However, the question is how risk management could directly influence project performance?. In other words, this relationship that was examined by many studies in the past but none in Oman.Accordingly, this study assumes that most projects in Oman are lacking assessment to certain risk management skills as one of the major issues facing construction projects in Oman, amy project managershave weak familiarity with formal risk management practices. Therefore, the author suggests that failure of many construction projects in meeting deadlines, cost and quality targets is continuously on the rise and there are signs of accentuating year after year suffering significant financial losses. A combination of the above issues led to an increasing failure of many construction projects in Oman in meeting deadlines, cost and quality and project targets, where the defects of all these factors are weakening construction project performance. Therefore, the problem statement of this study lies in understanding how risk management pinfluence the perofrmance of construction projects in Oman.

\section{Methodology}

The methodology used in this study is a quantitative approach based on causal and correlation research strategy. Quantitative research is subjective by observation and empirical data, which means that quantitative approach, is mainly concerned with evaluating the cause and effect of specific phenomena and then uses the collected data by empirical observation methods. The survey has conducted in construction industry, which registered in the Oman Tender Board, all companies from grade excellent to grade second in Oman selected. In the case of this research, stratified random sampling desired because stratified sampling offers several advantages over simple random sampling. The total number of questionnaire forms that have been distributed $=400$, the total number of valid questionnaire received after collecting the data from the respondents $=376$. The source of the questionnaire has been adopted from Ling (2017) and John (2008).

\section{The Concept of Risk Management}

Risk management (RM) is a concept that is becoming very popular in many companies. Many companies often implement risk management in their projects to increase productivity and increase profits as well improve business performance (Ahmadi et al., 2017). Risks and uncertainties are two of the most widely used concepts in the project management literature (Hopkinson, 2017; Qureshi et al., 2020)). Although these terms are closely related, many writers distinguish them (Lachapelle \& Hundozi, 2018). It is also difficult for workers at risk to identify and distinguish them. The definition of risk or uncertainty regarding the use of a particular project is often adjusted. To systematize, literary studies have been conducted. The findings of this research led to several definitions of risks and uncertainties (Ahmadi et al., 2017). 
Risk management is receiving much attention, as it seen as a method to improve cost, schedule, and technical performance of new product development programs (Aven, 2016). Uncertainty is one of the most important risk factors in projects that can be considered as a random event of an event where the probability is actually unknown, which means that the uncertainty is due to the occurrence of a little-known event, except that it can happen. (Bazin, 2017). However, it should be underlined that risk management is not a tool which ensures success but rather a tool which helps to increase the probability of achieving success. Risk management is therefore a proactive rather than a reactive concept (Ahmadi et al., 2017).

A number of definitions can be found in the literature, for example, Bahamid \& Doh (2017) explains the essence of this concept: The risk management process involves the systematic application of management policies, processes and procedures for contextual tasks, identification, analysis, evaluation, treatment, monitoring and risk communication (Bahamid \& Doh, 2017). Bazin (2017) described the Risk Management Process (RMP) is the important principle of risk assessment and risk management in the project. It includes the following key steps: identification, evaluation and analysis and response. All stages of the risk management plan should be included in the risk decision for the effective implementation of the process in the project. In the literature, there are many variants of the RMP, but the most frequently used frames consist of the above steps. Some models add a new step and most sources identify it as monitoring or risk management.

Dario (2017) suggested that projects are characterized as fragmented, temporary and complex, which in itself leads to risks. Industry decision-makers need reliable access to information and knowledge to be able to manage risks adequately and systematically. The introduction of effective risk management in the management of project management associated with it can therefore contribute to the success of any project. Bazin (2017) contains a detailed description of the RM concept and its practical application. In their opinion, risk management can not be considered as a tool for forecasting the future, because it is absolutely impossible. Instead, they describe this as an instrument that facilitates the project to make more effective decisions based on investment information. Thus, decisions based on insufficient information can be avoided, which will lead to an increase in overall productivity.

It is found that the difference and the relationship between uncertainty and risk can be described as a measurable risk of uncertainty, while uncertainty is the greatest risk. There is a correlation between uncertainty about the targeted targets, which means that only the relevant uncertainties that can affect the project's goals can pose a risk. In other words, the risk is an uncertainty that is important and the meaning is intended for specific purposes (Dario, 2017, Qureshi et al., 2020).

Carvalho \& Rabechini (2015) agreed that general skills at the organizational level affect risk and uncertainty. For example, organizational culture can make a difference. Soderlund and Gallego, (2017) indicate that risk is often controlled by the overall skills of the project team. According to Bazin (2017), there have been important efforts among international researchers in the field of international project to identify and rethink about the best skills of risk management and its influence on project performance.

\section{Risk Management in the Construction Industry}

A typical risk management project has five stages but however the aim of the traditionally project risk management is about looking for threats or negative risk in general and below figure- 2 is a visualized project risk management process (Bahamid \& Doh, 2017; Hillson, 2020). 
Figure-2: The risk management process (Hillson, 2020; Bazin 2017)

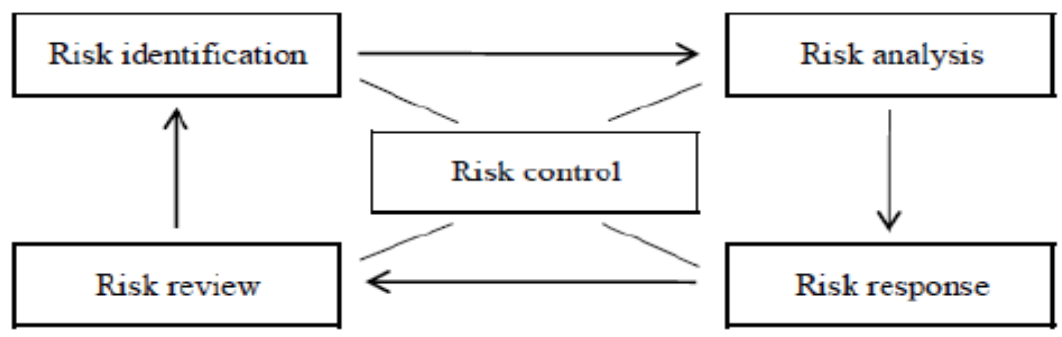

Pialles (2017) describes the model as a circular project that emphasizes that risk management is a time-learning process that uses the same four elements or steps as Bazin (2017) and Hillson (2020). In the literature, the basic premise of risk management is the same, but the process may vary by sector and organization. A typical risk management process starts with a definition phase; the purpose of this phase is to establish the context. This is both to Bahamid \& Doh (2017) and Hillson (2020) seen as an important phase due to in this phase the objectives for the project are being understood and agreed on. The output of this phase is a definition document with the purpose to record the decision on the scope and details of the risk process, this document is often called a Risk Management Plan (Hillson, 2020).There are many risk management methods or models in various small and medium projects, but the main risk management process involves four stages namely: Identification and classification of sources of risk, analysis of risk assessments, development of a risk management response and monitoring and control (Bazin 2017).

The risk management framework followed at Nokia Siemens Networks provides guidelines for (Ogunde et al., 2017):

- Continuous risk identification

- Risk evaluation

- Risk mitigation and contingency measure definition

- Risk monitoring and control

- Risk identification efficiency measurement

The risk management framework also provides templates and tools, such as (Nisar et al, 2017):

- A risk register for each project to track the risks and issues identified

- A risk checklist, which is a guideline to identify risks based on the project life cycle phases

- A risk repository, which is all the risks identified across projects so far.

The risk management approach allows organizations to observe and identify all the risks associated with a project in the hope of making an informed decision with a consistent and economical use of resources to control and reduce the impact and overall probability of a project. events considered undesirable (Dehdasht et al., 2015). Thus, transparency is enhanced by risk management and the project can be prepared for the inevitable problems.Many risks may also differ from the beginning by preventive measures of the project (Rostami, 2016).

\section{The practices of Risk Management Process}

As mentioned earlier, risk management process is the identification, evaluation, and prioritization of risks (defined in ISO 31000 as the effect of uncertainty on objectives) followed by coordinated and economical application of resources to minimize, monitor, and control the probability or impact of unfortunate events or to maximize the realization of opportunities (Crnković \& Vukomanović, 2016).

Risks can come from various sources including uncertainty in financial markets, threats from project failures as shown in Figure-3 (at any phase in design, development, production, or sustainment lifecycles), legal liabilities, credit risk, accidents, natural causes and disasters, deliberate attack from an adversary, or events of uncertain or unpredictable root-cause. 
Figure-3: The Theory of Risk Management (Crnković \& Vukomanović, 2016).

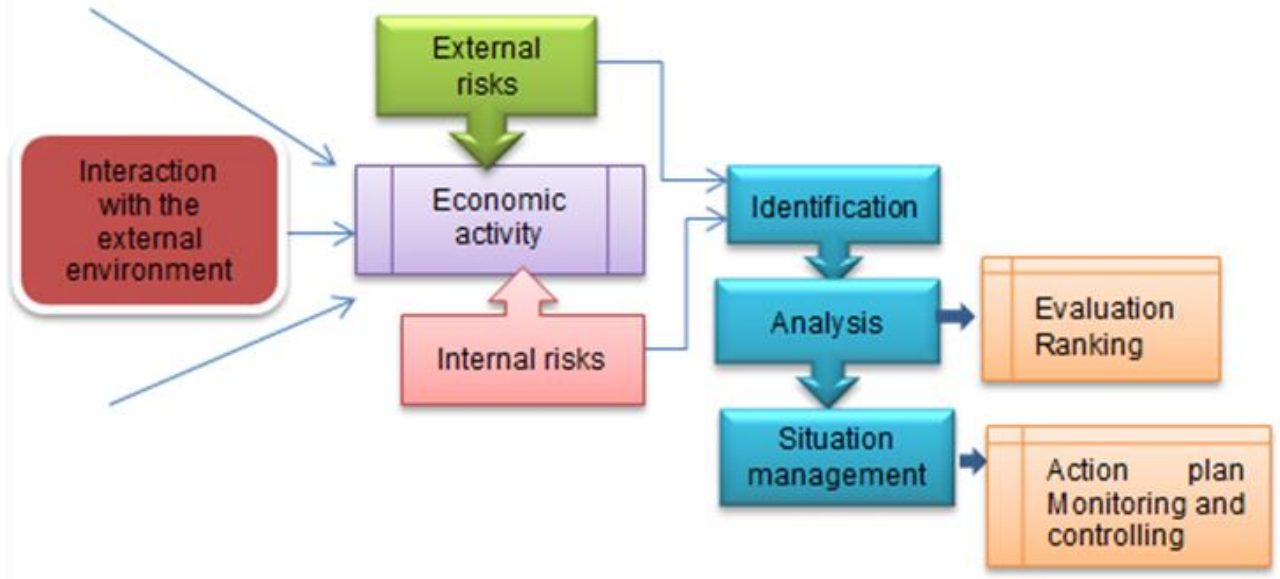

Two types of events i.e. negative events can classified as risks while positive events classified as opportunities. Several risk management standards have developed including the Project Management Institute, the National Institute of Standards and Technology, actuarial societies, and ISO standards. Methods, definitions and goals vary widely according to whether the risk management method is in the context of project management, security, engineering, industrial processes, financial portfolios, actuarial assessments, or public health and safety (ISO Guide 73: 2009).

\section{The impact of risk management on construction performance}

Risk management is directly associated with performance of construction projects. Aarthipriya et al., (2020) showed that there is existence of impact between risk identification and risk assessment on the project success, planned budget, schedule time, and complying with technical specifications. Another study by Lawrence (2015) indicated a strong connection between risk management and project performance in construction industry. He found that risk management practices at planning stage had an effect on project performance. The research project indicated that most projects had some input from a qualified engineer and architect. However most respondents had not studied risk management. Adeleke et al., (2018) have investigated the impact of risk management on project performance. The objective of their study is to measure the degree of diffusion of risk management practice in Brazilian companies. The results demonstrate that adopting risk management practices has a significant positive impact on project performance. They also show a positive impact from the presence of a risk manager on project success.

The review of previous studies revealed a strong association between risk management and performance of construction projects. A statement that "a higher risk may lead to a higher gain" (AlAjmi \& Makinde, 2018). Minimizing the risks in projects will improve the output of projects. Risks have a significant impact on a construction project's performance in terms of cost, time and quality (Chang et al., 2018). As the size and complexity of the projects have increased, an ability to manage risks throughout the construction process has become a central element preventing unwanted consequences. Moreover, risk management recognized as an important exercise in order to achieve better performance of construction projects. Success in construction project indicated by its performance in the achievement of project time, cost, quality, safety and environmental sustainability objectives. The research of Lawrence (2015) indicated that risk management practices at planning stage had an effect on project performance.

It is recommended that more attention be placed on organizing risk management according to their effect and influence and more emphasis should be put on communication and project risk management by developing plans for effective communication and risk handling when carrying out projects (Cross, 2019). In the same context, Hartono et al., (2019) examined the impact of project risk management on CPP. The results of their study showed that adopting Project Risk Management Practices has a significant positive impact on project success. They also show a positive impact from 
the presence of a risk manager on project success. From the practical point of view, paying attention to uncertainties during the project, making use of the project risk management techniques and deeply understand the business environment are critical success factors, demanding attention of project managers and risk managers. While Abazid \& Harb (2018) carried out in order to obtain a comprehensive conceptualization on risk and the consequences it has in the fields of construction and the required management operation. Along with the utilities and techniques adopted to control risk in the construction industry, the effect of risk on the project assessment also discussed. Based on the findings of previous studies, the following hypothesis statement examined in the empirical part of this research:

\section{Hypothesis 1: "project risk management has a significant effect on project performance in construction industry in Oman"}

\section{Results and discussions}

This section presents the quantitative analysis of data collected from the participants in the survey, which conducted at local construction companies in Oman. The respondents represent the project managers in these companies. The results from the statistical methods is used to answering research questions, examining the relationships between the independent variables of the study is project risk management (hereafter referred RM), while the dependent variable is project performance (hereafter referred PP). The analysis in this chapter based on regression methods and SEM approaches. The aim of analysis is to examine the hypothesis of this study. The data has collected from the survey after distributing questionnaire to the study sample and filtering the received questionnaire sheets. Following this stage, the researcher filled the data in SPSS file. Examining the output data in Table-1 shows the estimates (covariance) between the factors of RM namely: Risk identification, risk analysis, risk evaluation, risk response. Reading the output data in this table reveals that the magnitudes of estimates within the permissible cut-off points (Tabachnick \& Fidell, 1996; Hair et al., 2010). While C.R ranging between (2.165 and 5.727), all magnitudes are exceeding 1.96 the cut-off point (Chen et al., 2001; Garson, 2005; Tong, 2007).

Therefore, this study concludes there is a validated relationship between the factors. These associations are significant (Sig. $=0.000 \leq 0.05$ ). RMSEA $=0.044$ below the cut-off point $(0.08)$. CFI $=$ 0.960 high beyond the cut-off point (0.90). Finally, the factor loadings of of all factors are greater 4 than 0.10 (loading threshold).

Table -1: The Estimates of risk management

\begin{tabular}{|c|c|c|c|c|c|c|}
\hline \multicolumn{2}{|c|}{ Covariance Relationships } & Estimate & S.E. & C.R. & Sig \\
\hline Risk Analysis & $<$ & Risk Evaluation & .067 & .031 & 2.165 & 0.000 \\
\hline Risk Analysis & $<$ & Risk Response & .208 & .044 & 4.695 & 0.000 \\
\hline Risk Analysis & $<>$ & Risk Identification & .174 & .045 & 3.897 & 0.000 \\
\hline Risk Evaluation & $<>$ & Risk Response & .187 & .033 & 5.727 & 0.000 \\
\hline Risk Evaluation & $<>$ & Risk Identification & .131 & .029 & 4.515 & 0.000 \\
\hline Risk Response & $<>$ & Risk Identification & .194 & .038 & 5.132 & 0.000 \\
\hline
\end{tabular}

The result of CFA analysis lead to a conclusion that RM influenced by four factors, this influence is strong and statistically significant. Therefore, the association between these four factors is validated and constructing one measurement model. The justification of hypothesis shows that all values of C.R $=2.659 \geq 1.96$. The results revealed that risk management has a significant and positive relationship with project performance. 
Figure-3: Measurement model of risk management

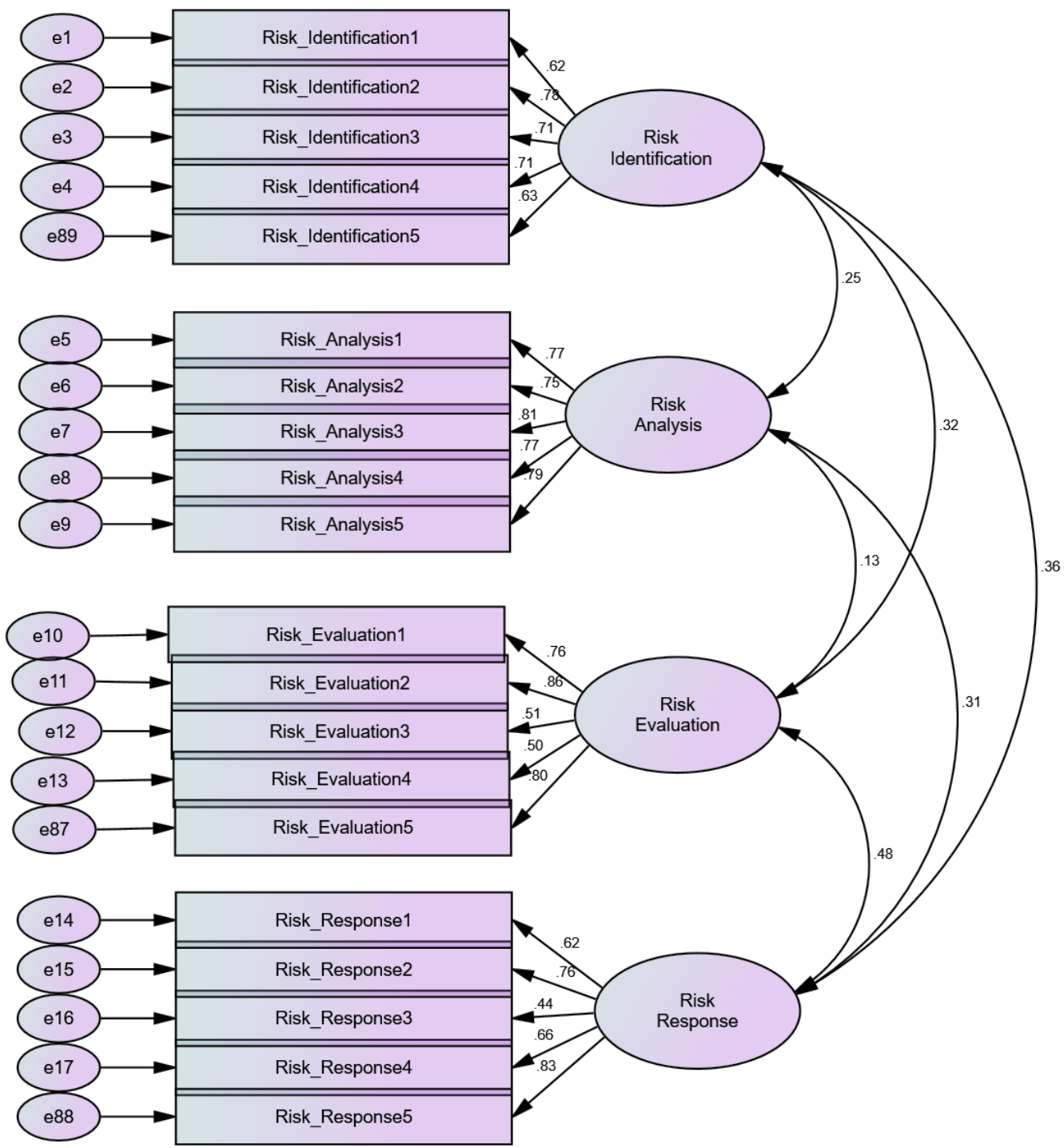

\section{Conclusion}

Risk management is a concept that is becoming very popular in many companies. Many construction companies often implement risk management in their projects to increase productivity and increase profits as well improve the overall performance. The analysis and discussion in this study based on SEM analysis methods. The hypothesis between risk management and project performance has examined in construction industry of Oman. The result revealed that practicing risk managementimprove the performance of construciton project significantly. Based on this result it is essential to hire qualified project managers who has sufficient knowledge in risk managmeent and its main activities.

Although this research has answered the main research questions and successfully tested the relationship between project risk management has a significant effect on project performance in construction industry in Oman, but conducting this research were not without certain limitations and constraints. Whereas the researcher suggests to test the theory presented in this study, it is recommended to make further validations to the hypothesis of this study in other countries in Middle East region or other countries in the world. Future research could be conducted to identify a revised competency framework for project performance which includes other factors associated with project 
perofrmance, epseciallt in schedule, budget, and cost dimensions. Further data collection through interviews, surveys, focus group discussion in other industries is recommended as well.

\section{References}

1. Aarthipriya, V., Chitra, G., \& Poomozhi, J. (2020). Risk and its impacts on time and cost in construction projects. Journal of Project Management, 5(4), 245-254.

2. Abazid, Mohammad \& Harb, Husameddin. (2018). an overview of risk management in the construction projects. Academic Research International. 9(1).

3. Adeleke, A., Bahaudin, A., Kamaruddeen, A., Bamgbade, J., Salimon, M. G., Khan, M. W. A., Sorooshian, S. (2018). The influence of organizational external factors on construction risk management among Nigerian construction companies. Safety and health at work, 9(1), 115-124.

4. Ahmadi, M., Behzadian, K., Ardeshir, A., \& Kapelan, Z. (2017). Comprehensive risk management using fuzzy FMEA and MCDA techniques in highway construction projects. Journal of Civil Engineering and Management, 23(2), 300-310.

5. Al-Ajmi, H. F., \& Makinde, E. (2018). Risk Management in Construction Projects. Journal of Advanced Management Science Vol, 6(2).

6. Aven, T. (2016). Risk assessment and risk management: Review of recent advances on their foundation. European Journal of Operational Research, 253(1): 1-13.

7. Bahamid, R. A. and Doh, S. I. (2017). A review of risk management process in construction projects of developing countries. In: IOP Conference Series: Materials Science and Engineering:

8. Bazin, N. (2017). Project and risk management - 4. Initiation of Risks Management Plan. 13-16 February 2017: VIA University College, Denmark.

9. Chang, T., Hwang, B.-G., Deng, X., \& Zhao, X. (2018). Identifying political risk management strategies in international construction projects. Advances in Civil Engineering, 2018.

10.Crnković, D. and Vukomanović, M. (2016). Comparison of trends in risk management theory and practices within the construction industry, e-GFOS 7(13) 1-11

11.Cross, Ogohi \& Daniel, Cross. (2019). Effect of Project Management on the Performance of Selected Construction Firms in Nigeria. 2347-3002.

12.Dehdasht, G., Zin, R. M., \& Keyvanfar, A. (2015). Risk Classification and Barrier of Implementing Risk Management in Oil and Gas Construction Companies. Journal Teknologi, 77(16).

13.Desai, A. and Kashiyani, B., (2015). Role of insurance as a risk management tool in construction projects. International Journal of advanced Research in Engineering Science and Management, 2(3), pp.202-217.

14.Fidell, S., Silvati, L., Howe, R., Pearsons, K. S., Tabachnick, B., Knopf, R. C \& Buchanan, T. (1996). Effects of aircraft over flights on wilderness recreationists. The Journal of the Acoustical Society of America, 100(5), 2909-2918.

15.Gabriella Cserhati and Lajos Szabo. (2013). the relationship between success criteria and success factors in organizational event projects. Elsevier. International Journal of Project Management. JPMA-01562, 12 pages,

16.Gallego Navarro, T. (2017). Looking for opinions about Quality and Risk Management. (Personal communication, 07 April 2017).

17.Garson, B. (2005). Work addiction in the age of information technology: An analysis. IIMB Management Review, 17(1), 15-21.

18.Gitau, Lawrence Mwangi. (2015). the effects of risk management at project planning phase on performance of construction projects in Rwanda. Jomo Kenyatta University of Agriculture and Technology, p. 1-76.

19.Hair, J. F., Black, W. C., Babin, B. J., \& Anderson, R. E. (2010). Multivariate data analysis (7ed.). Upper Saddle River, NJ, USA: Prentice-Hall, Inc.

20.Hartono, B., Wijaya, D. F., \& Arini, H. M. (2019). The Impact of Project Risk Management Maturity on Performance: Complexity as a moderating variable. International Journal of Engineering Business Management, 11, 1847979019855504. 
21.Hessellund, R., B. (2017). Civil Engineering - Risk Management \& Uncertainty - Version 1.2. [Reading] 6-10 March 2017: VIA University College, Denmark.

22. Hillson, D., \& Simon, P. (2020). Practical project risk management: The ATOM methodology. Berrett-Koehler Publishers.

23. Hopkinson, M. (2017). The Project Risk Maturity Model: Measuring and improving risk management capability. Routledge.

24.John, N.C.C. (2008). Predictors of Project Success: A Singapore Study. PhD Thesis. University of Western Australia.

25.Kerzner, H. (2018). Project management best practices: Achieving global excellence. John Wiley \& Sons.

26.Lachapelle, E., \& Hundozi, B. (2018). ISO 31000:2018, Risk management-guidelines, www.pecb.com

27.Ling, K.Z. (2017). Comparing the project success factors perceived by the project managers of different industries in Malaysia. Master Thesis. Universiti Tunku Abdul Rahman: Malaysia.

28. Marly Monteiro de Carvalho \& Roque Rabechini Junior (2015) Impact of risk management on project performance: the importance of soft skills, International Journal of Production Research, 53:2, 321-340,

29.Ogunde, A.; Joshua, O.; Amusan, L.M.; Akuete, E. (2017). Project management a panacea to improving the performance of construction project. Int. J. Civ. Eng. Technol., 8, 1234-1242

30.Petrovic, Dario. (2017). Risk management in construction projects: A knowledge management perspective from Swedish contractors.

31.Pialles, T. (2017). Study of the Coherences and Dependencies between Quality and Risk Management, within the Construction Industry.

32.Qureshi, M. I., Khan, N., Qayyum, S., Malik, S., Sanil, H. S., \& Ramayah, T. (2020). Classifications of sustainable manufacturing practices in ASEAN region: A systematic review and bibliometric analysis of the past decade of research. In Sustainability (Switzerland) (Vol. 12, Issue 21, pp. 1-19). MDPI AG. https://doi.org/10.3390/su12218950

33. Rostami, A. (2016). Tools and Techniques in Risk Identification: A Research within SMEs in the UK Construction Industry, Universal J. Manag. 4(4) 203-210

34.Singh, N. P., \& Hong, P. C. (2020). Impact of strategic and operational risk management practices on firm performance: An empirical investigation. European Management Journal, 38(5), 723-735.

35.Sen, S., Kotlarsky, J., \& Budhwar, P. (2020). Extending organizational boundaries through outsourcing: toward a dynamic risk-management capability framework. Academy of Management Perspectives, 34(1), 97-113.

36.Tong-Jian, Z. H. A. N. G. (2007). The evaluation system research of operational risk management performance in commercial banks in China under the new base capital accord. Journal of Guangdong University of Business Studies, 5(011).

37.Wu, Z., Nisar, T., Kapletia, D., \& Prabhakar, G. (2017). Risk factors for project success in the Chinese construction industry. Journal of manufacturing technology management, 28(7), 850-866. 